\title{
ESPAÇO, INIQUIDADE E TRANSPORTE PÚBLICO: AVALIAÇÃO DA ACESSIBILIDADE URBA- NA NA CIDADE DE NATAL/RN POR MEIO DE INDICADORES DE SUSTENTABILIDADE
}

\author{
Space, iniquity and public transportation: assessment of urban accessibility in the Natal/RN city \\ through sustainability indicators
}

Luzimar Pereira da Costa

Universidade Federal do Rio Grande do Norte, Natal, Rio Grande do Norte, Brasil luzzymar@yahoo.com.br

Ione Rodrigues Diniz Morais Universidade Federal do Rio Grande do Norte, Natal, Rio Grande do Norte, Brasil ionerdm@yahoo.com.br

Artigo recebido em 05/11/2013 e aceito para publicação em 21/02/2014.

RESUMO: Na atualidade, a mobilidade urbana configura um dos principais desafios das grandes e médias cidades brasileiras, haja vista os sinais de insustentabilidade que apresenta em relação a muitos aspectos que a envolve. Nas referidas cidades, onde a concentração de riqueza, terra e poder contrastam com a distribuição desigual da renda, a reprodução de iniquidades e os problemas cotidianos resultantes da acelerada urbanização afetam a mobilidade e acessibilidade urbanas. No tocante à acessibilidade urbana, a renda e a valorização de determinados espaços, aliadas a maiores investimentos em infraestrutura, fazem com que as áreas centrais das cidades apresentem melhores condições que as áreas periféricas. Diante do exposto, este trabalho tem como objetivo analisar as condições de acessibilidade urbana na cidade de Natal/RN e verificar em que medida o acesso a serviços e equipamentos urbanos é facilitado ou dificultado em virtude da localização da população e do seu poder aquisitivo. Adotou-se, como procedimentos metodológicos, a pesquisa bibliográfica e documental, bem como aferição e análise de alguns dos indicadores de sustentabilidade relacionados à acessibilidade urbana, que compõem o Índice de Mobilidade Urbana Sustentável (IMUS).

Palavras-chave: mobilidade urbana, acessibilidade urbana, reprodução do espaço, índice de mobilidade urbana sustentável.

ABSTRACT: Nowadays, the urban mobility appears as one of the main challenges of large and medium cities in Brazil, because it has signs of unsustainability relative to many aspects that involves it. In Brazilian cities, where the wealth concentration, land and power contrast with an irregular income distribution, the reproduction of inequalities and daily problems resulting from rapid urbanization affecting urban mobility and accessibility. Particularly in relation to urban accessibility, the income and the valuation of certain spaces, combined with efficient infrastructure, make the central areas have better conditions when compared to peripheral areas. In this manner, this paper intends to analyze the conditions of urban accessibility in Natal / RN and verify to what extent access to urban services and equipments is facilitated or difficulted because of the location and the purchasing power of its population. Therefore, the methodological procedures utilized were bibliographic and documentary surveys, as well as analysis of some of the sustainability indicators related to urban accessibility that comprise the Index of Sustainable Urban Mobility (I_SUM).

Keywords: urban mobility, urban accessibility, reproduction of space, sustainability indicators, index of sustainable urban mobility. 
Espaço, iniquidade e transporte público: avaliação da acessibilidade urbana na cidade de Natal/RN por meio de indicadores de sustentabilidade Luzimar Pereira da Costa, Ione Rodrigues Diniz Morais

\section{INTRODUÇÃO}

No Brasil, a expansão periférica e a segregação socioespacial associadas às precárias condições dos sistemas de transporte e de infraestrutura nas cidades têm prejudicado a dinâmica econômica e a qualidade de vida da população no que diz respeito à mobilidade e acessibilidade urbanas.

De acordo com Pereira (2008), a estruturação urbana em países capitalistas interfere no cotidiano dos citadinos à medida que estes se locomovem em busca de atendimento a demandas de trabalho e serviços, como práticas religiosas, educação, saúde e lazer, as quais se encontram dispersas na cidade e são necessárias à reprodução social. Desse modo, a situação espacial de cada indivíduo pode facilitar ou dificultar esses deslocamentos, assim como o poder aquisitivo, que definirá os meios de locomoção a serem utilizados para que ocorram o uso e a apropriação do espaço urbano.

Em Natal, capital do Rio Grande do Norte, a ocupação periférica da cidade, sem o devido planejamento, tem aumentado, consideravelmente, a necessidade de transporte e serviços públicos de infraestrutura, os quais, frequentemente, não têm suprido a demanda adequadamente.

No que se refere à história da ocupação do solo urbano de Natal, Costa (2000) sinaliza que o crescimento da cidade, mesmo com as intervenções e os planos urbanísticos, ocorreu de forma tendenciosa à segregação do espaço entre as classes de alta renda $\mathrm{e}$ as classes de baixa renda, tendo em vista que o padrão de infraestrutura adotado propiciou maior valorização da área mais central, fazendo com que as pessoas de baixa renda ocupassem a periferia, onde há ausência de uma infraestrutura adequada.

Gomide (2006) argumenta que o impacto da ocupação periférica nas cidades, sem que ocorra um planejamento adequado, impõe uma das piores iniquidades, a da acessibilidade urbana. A inadequação na oferta dos serviços em áreas periféricas somada às altas tarifas do transporte público, além de prejudicar a parcela mais pobre da população, restringindo as oportunidades de trabalho e de acesso aos serviços de saúde, educação e lazer, tem estimulado o uso do transporte individual. Essa situação contribui para o aumento dos níveis de poluição e de congestionamentos e reforça os fenômenos da de- sigualdade de oportunidades e da segregação espacial, propiciadores de exclusão social.

Em relação ao sistema de transporte público de Natal, Torquato e Santos (2004) afirmam que algumas áreas mais centrais da cidade são atendidas de forma demasiada, já nas áreas periféricas, a situação de atendimento é deficitária. Diante da expansão da cidade, esse sistema de transporte já não atende às necessidades de forma lógica, pois conserva ainda uma grande oferta de viagens para a tradicional área central da cidade, embora o desejo de destino para essa área tenha decrescido. Já as áreas periféricas, especificamente, os bairros das regiões administrativas Norte e Oeste, apresentam uma oferta de viagens de transporte público por passageiro menor que a demanda, especialmente nos horários de maior fluxo.

Diante do exposto, objetiva-se analisar as condições de acessibilidade urbana em Natal e verificar em que medida o acesso a serviços e equipamentos urbanos é facilitado ou dificultado em virtude da localização e do poder aquisitivo de sua população. Como objetivos específicos, têm-se: avaliar, por meio de alguns indicadores proposto no Índice de Mobilidade Urbana Sustentável (IMUS) as condições de acessibilidade urbana em Natal e comparar a situação de acessibilidade entre bairros localizados em zonas distintas na cidade, em termos de acesso a equipamentos e serviços públicos urbanos.

Na perspetiva de compreender a problemática discutida e atingir os objetivos propostos, este trabalho busca suporte no uso de indicadores de sustentabilidade relacionados à mobilidade urbana. Pretende-se utilizar o Índice de Mobilidade Urbana Sustentável desenvolvido por Costa (2008), que se baseia nas dimensões da sustentabilidade (social, econômica, política, cultural, territorial e ambiental), e tem como referência pesquisas brasileiras e europeias e workshops em 11 cidades brasileiras.

A metodologia adotada para a realização deste trabalho consistiu em pesquisa descritiva exploratória, de natureza quantitativa e qualitativa, estando em consonância com um referencial bibliográfico por meio da qual realizou-se uma reflexão teórico-conceitual acerca do tema acessibilidade urbana, exclusão social e (re) produção do espaço. Também foi realizada pesquisa documental, princialmente, em orgãos públicos locais, 
possibilitando a aquisição de dados para avaliar os indicadores referentes à acessibilidade propostos no IMUS.

\section{MOBILIDADE, ACESSIBILIDADE E A PRODU- ÇÃO DO ESPAÇO URBANO}

Um estudo sobre a cidade pode enveredar por diferentes trilhas, dentre elas, a análise da dinâmica de crescimento urbano, incluindo as transformações que configuram a sua estruturação e, consequentemente, são responsáveis pelo processo de produção do espaço.

O termo produção do espaço, segundo Lefebvre (2000), visa responder aos processos de reprodução das relações capitalistas de produção. Ao formular sua teoria, esse autor considera o capitalismo um processo e o espaço como seu produto. Sendo assim, relações capitalistas se reproduzem no espaço e se refletem em manifestações de conflitos e contradições da sociedade.

Santos (2004, p. 21) conceitua espaço como um "conjunto indissociável de sistemas de objetos e sistema de ações". A produção do espaço, para o autor, significa a produção de objetos que articulam e organizam, em suas funções específicas, intercâmbios sociais que envolvem o trabalho. $\mathrm{O}$ espaço seria, nesse caso, a materialidade e a mediação entre os sistemas de controle, e a reprodução do trabalho se traduziria em sua dimensão técnica e material.

Nessa perspectiva, entende-se que o espaço produzido é susceptível a novas transformações pela sociedade. Sendo assim, o espaço produzido é usado para (re)fazer estruturas e para (re)construir a sociedade, desse modo surge também o termo (re)produção do espaço. De acordo com Silva Júnior e Rutkovski (2011), a (re)produção do espaço urbano nas cidades implica o avanço de novas técnicas que, ao se inserirem no espaço produzido pelo homem, desenvolvem novas estruturas e infraestruturas que perpetuam a produção do capital e da sociedade.

Segundo Santos (2004), a materialização das técnicas no espaço é determinante para que a mobilidade e acessibilidade se desenvolvam no espaço urbano. Nesse sentido, Mondardo (2009) alega que, para que o espaço urbano seja (re)produzido, é necessário que ocorra a mobilidade de pessoas, de objetos, de ações, de representações, de ideias, de mercadorias, dentre outros. O espaço urbano é um conjunto de elementos que se movem, interagem e são solidários e contraditórios, porque criam espaços diferenciados, cada um com sua função, com sua relação social.

Diante desse cenário discursivo, torna-se oportuna a compreensão do significado de mobilidade urbana que, por vezes, se confunde com acessibilidade urbana. No entanto, é importante esclarecer que, embora se completem, os termos possuem significados diferentes.

De acordo com Vasconcellos (2001), a mobilidade urbana refere-se ao ato de se movimentar de acordo com condições físicas e econômicas. A mobilidade implica a disponibilidade de meios de transporte, não motorizados e pessoais (a pé e de bicicleta) ou motorizados (públicos ou privados), e toda a infraestrutura para realizar os deslocamentos.

A esse respeito, Pereira (2008) alega que a mobilidade como um fim a ser obtido por um meio de transporte varia de acordo com a forma em que é realizada. Em alguns casos e situações, o deslocamento pelo espaço urbano ocorre a pé. À medida que a extensão territorial se amplia e parte dos equipamentos coletivos ainda permanece centralizada, faz-se necessário o deslocamento por meio de transporte motorizado. De acordo com a renda dos usuários, esses meios podem ser públicos e coletivos ou privados e individuais, sendo que a oferta, a qualidade, a eficiência e o tempo de deslocamento entre eles serão bastante diferenciados, implicando menor grau de acessibilidade dos que dependem do transporte público para se deslocar.

Portanto, a ideia de ligação física e temporal entre os meios de transporte e os destinos desejados requer uma melhor compreensão das diferenças entre uma visão simplista da mobilidade urbana pessoal e uma visão mais abrangente da acessibilidade.

Pereira (2008) afirma que a acessibilidade tem um enfoque mais amplo que o da mobilidade. Ao se tratar de acessibilidade, considera-se que há uma conexão entre a oferta do sistema de circulação e a estrutura urbana, que se refere ao modo como o indivíduo pode usar e (re)produzir o espaço da cidade.

Para Vasconcellos (2001), a acessibilidade é entendida como a facilidade ou dificuldade para a realização das necessidades que se refletem na produção do espaço. Já Litman (2012), a define como a facilidade de alcançar bens, serviços, atividades e 
Espaço, iniquidade e transporte público: avaliação da acessibilidade urbana na cidade de Natal/RN por meio de indicadores de sustentabilidade Luzimar Pereira da Costa, Ione Rodrigues Diniz Morais

destinos, que, juntos, são chamados de oportunidades.

Com o objetivo de aprofundar o entendimento sobre acessibilidade urbana, Cardoso (2008) a classifica em duas categorias. A primeira trata da acessibilidade ao sistema de transporte medida pela facilidade que o usuário dispõe para acessar o sistema de transporte coletivo em seu local de moradia, trabalho, dentre outros. A segunda categoria corresponde à acessibilidade a destinos, que pode ser entendida como a facilidade de se chegar ao local desejado após o acesso ao sistema de transporte.

Segundo Vasconcellos (2001), nas cidades brasileiras, a acessibilidade cresce conforme a renda e o espaço de circulação são acessados de forma desigual, refletindo a disparidade de condições socioeconômicas entre os cidadãos. Enquanto as famílias de renda mais baixa, segregadas espacialmente, têm uma mobilidade limitada e consomem menos espaço, ou seja, tem menor acessibilidade, as famílias de renda mais alta usam transporte mais rápido, o automóvel, para realizar mais viagens e consumir mais espaço.

Nesse sentido, é importante ressaltar que, na maioria dos casos, as pessoas de baixo poder aquisitivo, por não possuírem automóvel particular, usam o transporte público, possuindo menor acessibilidade e mobilidade devido às poucas opções de itinerários, frequência e custos. Desse modo, a renda apresenta-se como um dos principais elementos de avaliação das condições de acessibilidade urbana. Outro fator determinante para uma maior ou menor acessibilidade é a localização no espaço urbano. A acessibilidade não ocorre em igualdade de condições para todos os habitantes de uma cidade. Tal fato está relacionado ao processo de produção e reprodução do espaço urbano que reflete as iniquidades sociais.

Santos (1996) afirma que, nas cidades, as periferias são materializações de mecanismos de exclusão/diferenciação espacial, os quais adquirem visibilidade por meio de habitações insuficientes e de má qualidade, da inexistência de infraestrutura básica, da baixa possibilidade de acesso rápido e confortável aos lugares de trabalho e malha viária, bem como da ausência de equipamentos de transporte coletivo eficientes, evidenciando a desigualdade socioespacial.

Pode-se mencionar, como exemplo de desigualdade social, a segregação espacial imposta à população de baixo poder aquisitivo em áreas periféricas das cidades. De acordo com Villaça (2001, p.142), segregação socioespacial "é um processo, segundo o qual diferentes classes ou camadas sociais tendem a se concentrar cada vez mais em diferentes regiões gerais ou conjuntos de bairros da metrópole".

Desse modo, considera-se que, no modo de produção capitalista, o processo de segregação socioespacial não se desvincula das formas de (re)produção do espaço urbano. No âmbito desse sistema, ocorre a diferenciação socioespacial no interior da cidade, com áreas mais bem servidas de infraestrutura e de ofertas de bens e serviços; em contraposição, há outras que são precariamente providas. Segundo Villaça (2001), o valor de uso solo urbano é determinante para diferenciar as acessibilidades que cada fragmento urbano tem em relação ao todo e, consequentemente, à cidade, como cada bairro se comunica e se articula com o centro.

Diante dessa e de outras externalidades que envolvem a mobilidade urbana, é possível pensar que as cidades brasileiras vivem um momento de crise. Conforme reflexões realizadas por Litman (2003), essa situação exige uma mudança de paradigma. Trata-se de reverter o atual modelo de mobilidade, integrando-a aos instrumentos de gestão urbanística voltados para os princípios da sustentabilidade ambiental e para a inclusão social.

No Brasil, os princípios da sustentabilidade vêm sendo incorporados em diversas políticas de planejamento urbano. No que tange à mobilidade urbana, estes foram incorporados à Política Nacional de Mobilidade Urbana (PNMU), lançada em 2004 no PlanMob e instituída por meio da Lei 1.247 em 2012. O PlanMob prevê para a avaliação do impacto dessa política nas cidades brasileiras uma metodologia que envolve o estabelecimento de indicadores.

Ao longo dos últimos anos, a preocupação com o desenvolvimento sustentável tem incentivado o estudo e a implantação de estratégias em diversos setores de planejamento do governo, incluindo, como uma das principais pautas, a mobilidade urbana. É possível afirmar que, paralelamente, também tem crescido a necessidade de buscar ferramentas práticas que auxiliem na avaliação das ações de planejamento, destacando-se, nesse contexto, o uso de indicadores de sustentabilidade. 
ÍNDICE DE MOBILIDADE URBANA SUSTENTÁVEL (IMUS)

Na sociedade atual, amplia-se a importância da análise dos fenômenos socioespacias por meio de indicadores, sobretudo aqueles voltados para aferição do desenvolvimento urbano. Nesse processo, a identificação de indicadores que permitam avaliar o comportamento de determinados setores do planejamento urbano em relação aos princípios do desenvolvimento sustentável tornam-se fundamentais.

De acordo com Mourelo (2002), um indicador atende a uma dupla necessidade: por um lado, fornece a informação adequada para a tomada de decisões e, por outro, reduz uma grande quantidade de informações a um número de parâmetros de mais fácil controle, o que serve tanto para a tomada de decisões como para informar o público.

Aportada nessa lógica e considerando o contexto brasileiro, Costa (2008) propôs o Índice de Mobilidade Sustentável (IMUS) com o objetivo de oferecer uma metodologia capaz de avaliar quantitativamente e qualitativamente a mobilidade urbana, a partir de indicadores relacionados aos aspectos social, político, econômico, cultural e ambiental.

O IMUS consiste em uma ferramenta desenvolvida para auxiliar a avaliação e identificação dos aspectos críticos e de maior impacto que comprometem a mobilidade urbana, fornecendo subsídios para políticas públicas que visem à sustentabilidade dos sistemas de mobilidade e inclusão social.

Segundo Miranda e Rodrigues da Silva (2012), o IMUS foi formulado para atender tanto às questões voltadas para o planejamento tradicional quanto àquelas relacionadas à mobilidade sustentável.
Apresenta-se como um índice fácil de calcular e analisar, sendo flexível o suficiente para ser aplicado em cidades com características diversas. Seus indicadores são avaliados por um sistema de peso que os qualifica de maneira individual e em grupo. Sua composição se divide em 9 Domínios: acessibilidade, aspectos ambientais, aspectos sociais, aspectos políticos, infraestrutura, modos não motorizados, planejamento integrado, tráfego e circulação urbana e sistema de transporte urbano. Esses Domínios, por sua vez, se subdividem em 37 temas, totalizando 87 indicadores. O resultado do índice varia de 0,00 a 1,00 , sendo que quanto mais próximo estiver de 1,00 , o resultado tende a ser sustentável. O processo de normalização sugerido para chegar ao resultado baseia-se em valores de referência de normas brasileiras e internacionais encontrados na literatura, sendo os valores de referência existentes adaptados ao contexto das cidades brasileiras.

\section{CARACTERIZAÇÃO DA ÁREA DE ESTUDO}

O recorte espacial desta pesquisa corresponde à cidade do Natal, capital do Rio Grande do Norte, localizada na Microrregião homônima, que se insere na Mesorregião Leste Potiguar. A cidade encontra-se localizada sob as coordenadas geográficas: latitude $5^{\circ} 47^{\prime} 42$ " Sul e longitude: 35'12'34" Oeste (IDEMA, 2008). De acordo com o Censo Demográfico 2010 (IBGE), Natal possui 803.739 habitantes, 235.533 domicílios e uma taxa de urbanização de $100 \%$. A cidade está dividida em quatro Regiões Administrativas, constituídas por 36 bairros. Sua área compreende cerca de $170 \mathrm{~km}^{2}$, que equivalem a $0,32 \%$ da superfície estadual (Figura 1). 
Figura 1. Localização de Natal/RN

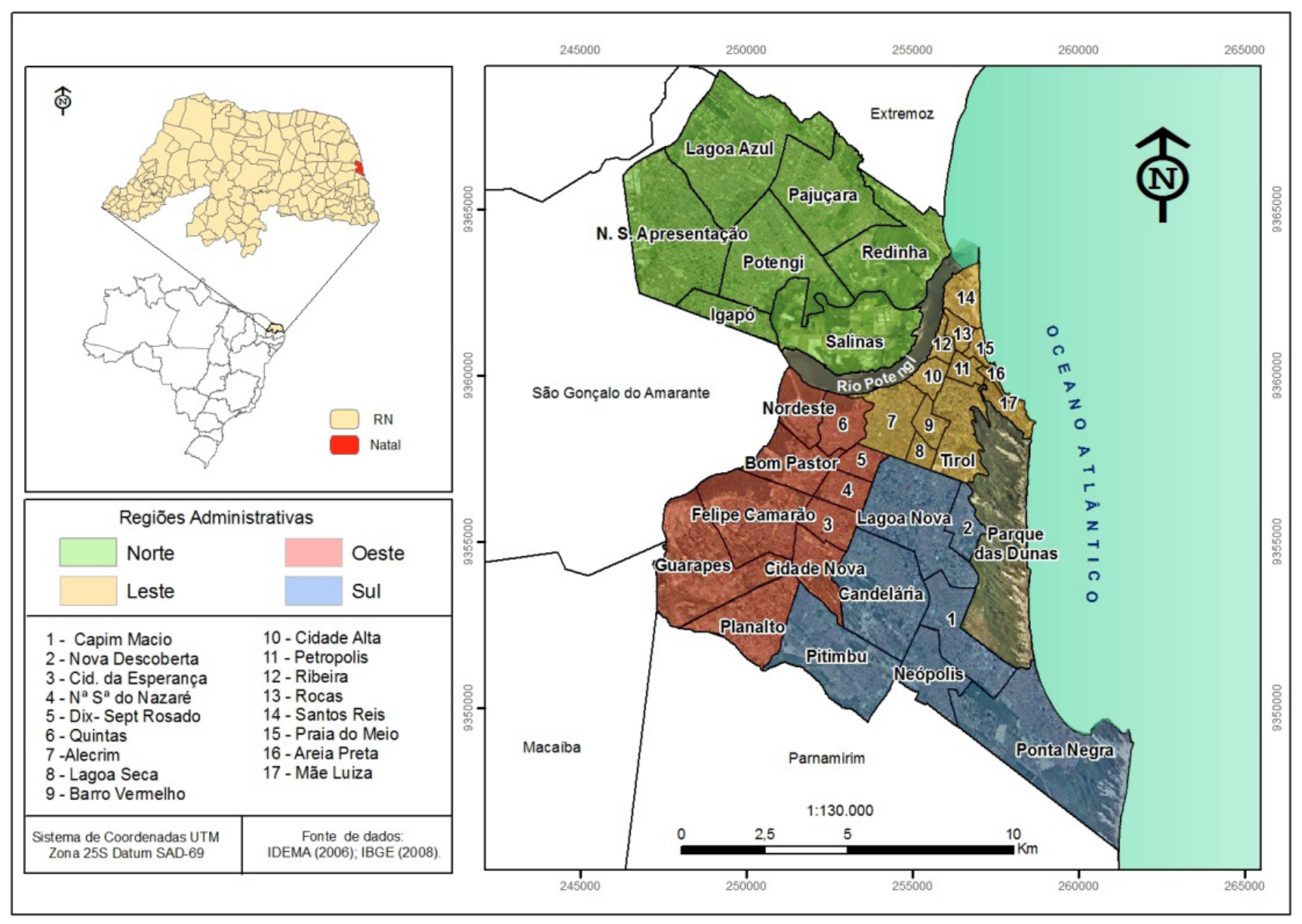

Org. das autoras.

\section{PROCEDIMENTOS METODOLÓGICOS}

A presente pesquisa fundamenta-se numa análise descritiva e exploratória. Segundo Gil (2007, p. 43), "uma pesquisa explicativa pode ser a continuação de outra descritiva, posto que a identificação de fatores que determinam um fenômeno exige que este esteja suficientemente descrito e detalhado".

A pesquisa foi realizada em consonância com a pesquisa bibliográfica e documental, utilizando-se da análise de natureza quantitativa e qualitativa, pois de acordo com Flick (2009), essas abordagens não são excludentes ou contrárias, mas se complementam uma à outra no processo de compreensão da realidade e construção do conhecimento.

Para avaliar as condições de acessibilidade urbana em Natal, foram selecionados alguns dos indicadores do IMUS relacionados ao Domínio
Acessibilidade e às Temáticas - Acessibilidade aos sistemas de transporte e Acessibilidade universal, sendo estes: Acessibilidade aos serviços essenciais, Acessibilidade aos espaços abertos e Acessibilidade ao transporte público.

Para a análise desses indicadores, foi necessário recorrer a bancos de dados espaciais sobre as Temáticas citadas, adquiridos, principalmente, na Secretaria Municipal de Mobilidade Urbana (SEMOB, 2010), Secretaria Municipal de Meio Ambiente e Urbanismo (SEMURB, 2013) e Institudo Brasileiro de Geografia e Estatística (IBGE, 2010). Como ferramenta auxiliar para essa análise, utilizou-se, basicamente, de Sistema de Informações Geográficas - Acgis 9.3 e de planilhas eletrônicas (Excel 2010).

De posse dos dados e com auxílio das referidas ferramentas foram feitas sobreposições do conjunto 
de arquivos georreferenciados de interesse para atender aos objetivos. Em seguida, foram criadas áreas com os respectivos raios de abrangência determinado no IMUS para cada um dos indicadores. Ex.: para o indicador de Acessibilidade ao transporte público foram criados raios de 300 metros no entorno das paradas de ônibus. Em seguida, considerando a junção dos áreas sobrepostas, foi gerada uma única área de abrangência total.

A partir do banco de dados georreferenciado de domicílios e dos setores censitários do IBGE (2010) situados em Natal, foi feita a contagem do domincílios dentro dessa área de abrangência e, posteriormente, foi realizada a subtração destes em relação ao total de domicílios registrados pelo Censo Demográfico do IBGE (2010), chegando, desse modo, ao percentual de domícilios situados dentro e fora da área de cobertura determinada para cada Indicador.

Para comparar as condições de acessibilidade a serviços e equipamentos públicos entre os bairros e Regiões Administrativas de Natal, foram elaborados mapas temáticos que ilustram as áreas cobertas e não cobertas pelo raio de abrangência, indicando maior e menor facilidade de acesso ao destino desejado. Posteriormente, através de planilha eletrônica, foram confeccionados gráficos a partir da contagem de domicílios por bairro externos às áreas de cobertura do respectivo indicador.

\section{RESULTADOS}

Neste artigo, são apresentados os principais resultados obtidos para Natal no que se refere à acessibilidade urbana. Primeiramente, é considerado o desempenho da cidade em face dos indicadores analisados. Num segundo momento, foram obtidos resultados da aplicação do método de avaliação em áreas distintas da cidade, o que permitiu compreender os diferentes cenários de acessibilidade no espaço urbano de Natal/RN.

\section{Acessibilidade aos serviços essenciais em Natal/RN}

A análise das condições de acessibilidade urbana para a população de Natal parte da localização dos domicílios e da posição em relação a outras edificações em que são prestados serviços essenciais, como escolas e unidades básicas de saúde públicas. A acessibilidade da população a esses serviços públicos depende do nível de provimento que apresentam, tal como o número de vagas nas escolas ou de atendimentos nos postos de saúde, assim como da distribuição da população e da forma de alcance desses equipamentos.

A forma de deslocamento utilizada pelo usuário é um fator que facilita ou dificulta o acesso ao serviço de saúde e de educação. Desse modo, quanto maior for a oferta e melhor a distribuição desses equipamentos, menor será o tempo gasto com deslocamento e menor será a necessidade de usar veículos motorizados, impactando, positivamente, a acessibilidade.

Diante disso, para o Indicador Acessibilidade aos Serviços Essenciais é considerado como ideal, uma distância de até 500 metros das unidades de saúde de atendimento básico e de escolas públicas em relação aos domicílios (COSTA, 2008).

Na cidade do Natal, são registrados 256 estabelecimentos públicos de educação, dos quais 58 são centros municipais de educação infantil (CMEI), 71 são escolas municipais, 120 são escolas estaduais e 07 são escolas federais (de educação infantil e ensino médio/técnico). Quanto aos estabelecimentos de saúde, a cidade possui 55 unidades de atendimento primário e 02 unidades mistas (SEMURB, 2013). A Figura 2 ilustra a distribuição espacial desses equipamentos públicos em Natal. 
Espaço, iniquidade e transporte público: avaliação da acessibilidade urbana na cidade de Natal/RN por meio de indicadores de sustentabilidade Luzimar Pereira da Costa, Ione Rodrigues Diniz Morais

Figura 2. Acessibilidade aos serviços essenciais (saúde e educação) em Natal/RN

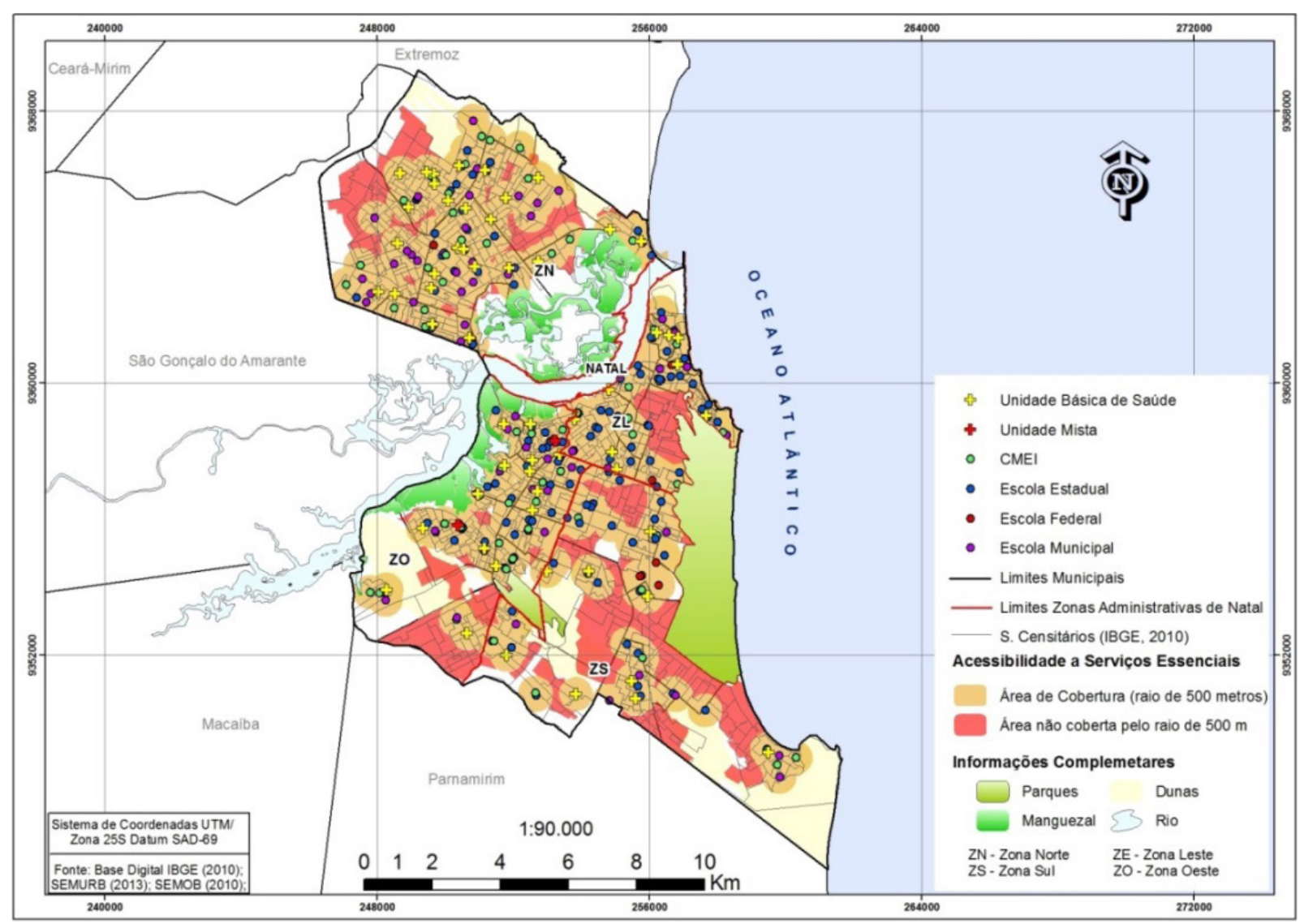

Org. das autoras.

De acordo com a distribuição espacial e a distância desses equipamentos em relação aos domicílios existentes na cidade, os resultados para esse indicador mostram que 187.570 dos 235.533 domicílios de Natal registrados pelo Censo Demográfico 2010 (IBGE), o que equivale a 79,64\%, localizam-se a uma distância inferior ou igual a 500 metros dos equipamentos de saúde e/ou educação. Desse modo, considerando a normalização proposta no IMUS, a avaliação para o indicador foi de aproximadamente 0,77 , podendo-se considerar que, em termos de Acessibilidade aos Serviços Essenciais, esse é um bom resultado para a cidade.

Todavia, uma parcela significativa da população apresenta maiores dificuldades de acesso a esses equipamentos em decorrência das distâncias. Esse aspecto assume nitidez quando se observa que 47.963 domicílios, equivalente a $20,36 \%$ do total de domicílios da cidade, se encontram fora da área de cobertura de serviços públicos de saúde e de educação. A maior quantidade de domicílios externa ao raio de cobertura encontra-se nas zonas Sul, Oeste e Norte da cidade (Figuras 2 e 3). Com exceção de alguns bairros localizados nas zonas Sul e Leste, os demais se situam em áreas periféricas que apresentam renda per capita baixa.

Entre os bairros que apresentam a maior quantidade de domicílios localizados num raio superior a 500 metros, portanto fora da área de cobertura, destacam-se o Bairro Planalto, na Zona Oeste; o Bairro Nossa Senhora da Apresentação na Zona Norte e, os bairros Capim Macio, Ponta Negra, Lagoa Nova e Candelária, na Zona Sul. Na Zona Leste, o único bairro que possui uma quantidade considerável de domicílios externos à área de cobertura de serviços públicos de saúde e de educação, é o de Tirol (Figura 3).

No entanto, salienta-se que o bairro de Tirol e o de Petrópolis, ambos localizados na Zona Leste, juntos concentram a maior quantidade de serviços de saúde mais complexos, incluindo tanto a rede pública quanto a particular e apresentam as duas maiores renda per capita da cidade. 
Figura 3. Domicílios externos ao raio de cobertura de 500 metros de serviços essenciais em Natal/RN

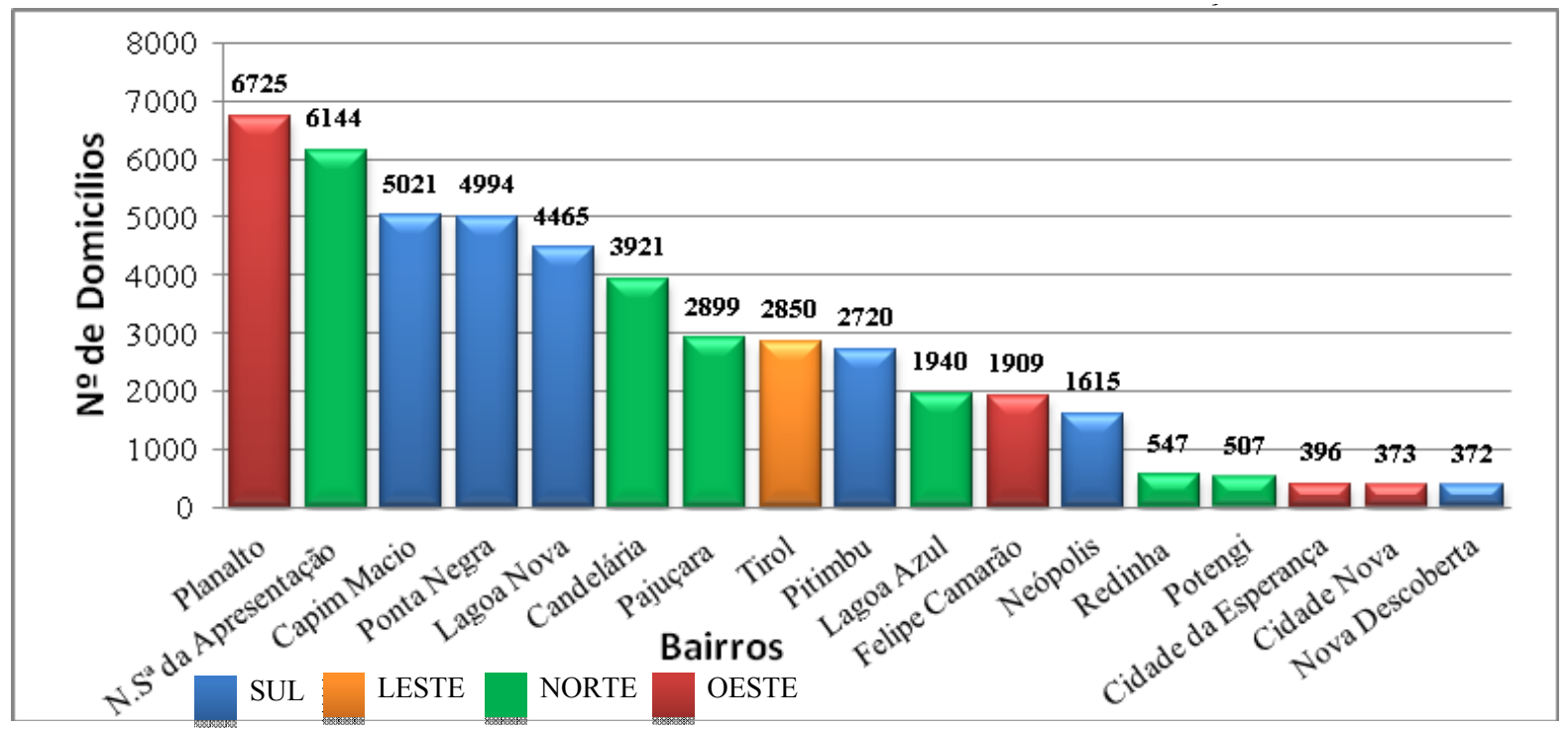

Org. das autoras.

Em contrapartida, os bairros Planalto, situado na Zona Oeste e Nossa Senhora da Apresentação na Zona Norte, considerados periféricos e cuja população é de baixa renda, juntos contabilizam $26,83 \%$ dos domicílios que têm problemas de acessibilidade aos serviços essenciais em decorrência da distância. É importante destacar que, em termos populacionais, estes são os dois bairros que mais cresceram em Natal, entre os anos de 2000 e 2010. De acordo com o Censo Demográfico 2010 (IBGE), a população do Bairro Planalto cresceu $117 \%$, passando de 14.314 habitantes para $31.206 \mathrm{em}$ dez anos. O Bairro Nossa Senhora da Apresentação, considerado o mais populoso da cidade desde 2000, cresceu $41 \%$, passando de 56.522 para 79.759 habitantes no mesmo período. Todavia, evidencia-se que investimentos em equipamentos de saúde e educação não cresceram na mesma proporção nesses bairros, de modo que uma fração considerável da população que neles reside realiza longos percursos, seja a pé, de bicicleta ou de veículo motorizado, para ter acesso a esses serviços, o que não é garantido em sua plenitude, pois a quantidade existente revela-se insuficiente.

Diante dos resultados apresentados até o momento, conclui-se que a cidade de Natal possui um déficit de equipamentos de saúde e de educação que afeta uma parte significativa da população da cidade, que reside nas zonas Sul, Norte e Oeste. No entanto, a camada da população de menor poder aquisitivo, que mora, principalmente nas duas últimas zonas citadas, é a mais afetada pelo problema, visto que, em sua maioria, não pode recorrer a serviços de plano de saúde e escolas privadas, diferentemente dos moradores da zona Sul, que possuem melhores condições econômicas.

\section{Acessibilidade a áreas abertas em Natal/RN}

Nesse indicador são avaliadas as distâncias dos domicílios em relação às praças, áreas verdes e parques. São considerados imersos na área de cobertura aqueles domicílios localizados a uma distância de até 500 metros de praças e outras áreas de recreação de pequeno e médio porte, e de 1.000 metros de parques urbanos.

Esses locais, além de lazer e recreação, desempenham outras funções importantes no meio urbano, como a presença de solo permeável essencial para infiltração da água da chuva, melhoria do clima e qualidade do ar e estética ligada à apreciação da paisagem, implicando melhorias na qualidade de vida da população.

Para Loboda e De Angelis (2005), a qualidade de vida urbana está diretamente atrelada a vários fatores como infraestrutura, desenvolvimento socioeconômico e àqueles ligados à questão ambiental. No caso do ambiente, as áreas verdes públicas constituem- 
Espaço, iniquidade e transporte público: avaliação da acessibilidade urbana na cidade de Natal/RN por meio de indicadores de sustentabilidade Luzimar Pereira da Costa, Ione Rodrigues Diniz Morais

-se elementos imprescindíveis para o bem-estar da população, pois influenciam diretamente na saúde física e mental.

A Cidade do Natal possui 252 praças, das quais 90 localizam-se na Zona Sul; 72 na Zona Leste; 60 na Zona Norte e 29 na Zona Oeste. As áreas verdes de pequeno porte somam 581, correspondentes a canteiros, reservas florestais, praças, quadras, áreas reservadas ou remanejadas pela prefeitura, entre outros. No que se refere aos parques, a cidade possui dois: o Parque Estadual das Dunas e o Parque da Cidade Dom Nivaldo Monte. O primeiro localiza-se entre as zonas Sul e Leste e o segundo entre as zonas Sul e Oeste da cidade (Figura 4).

Figura 4. Acessibilidade aos espaços abertos em Natal/RN

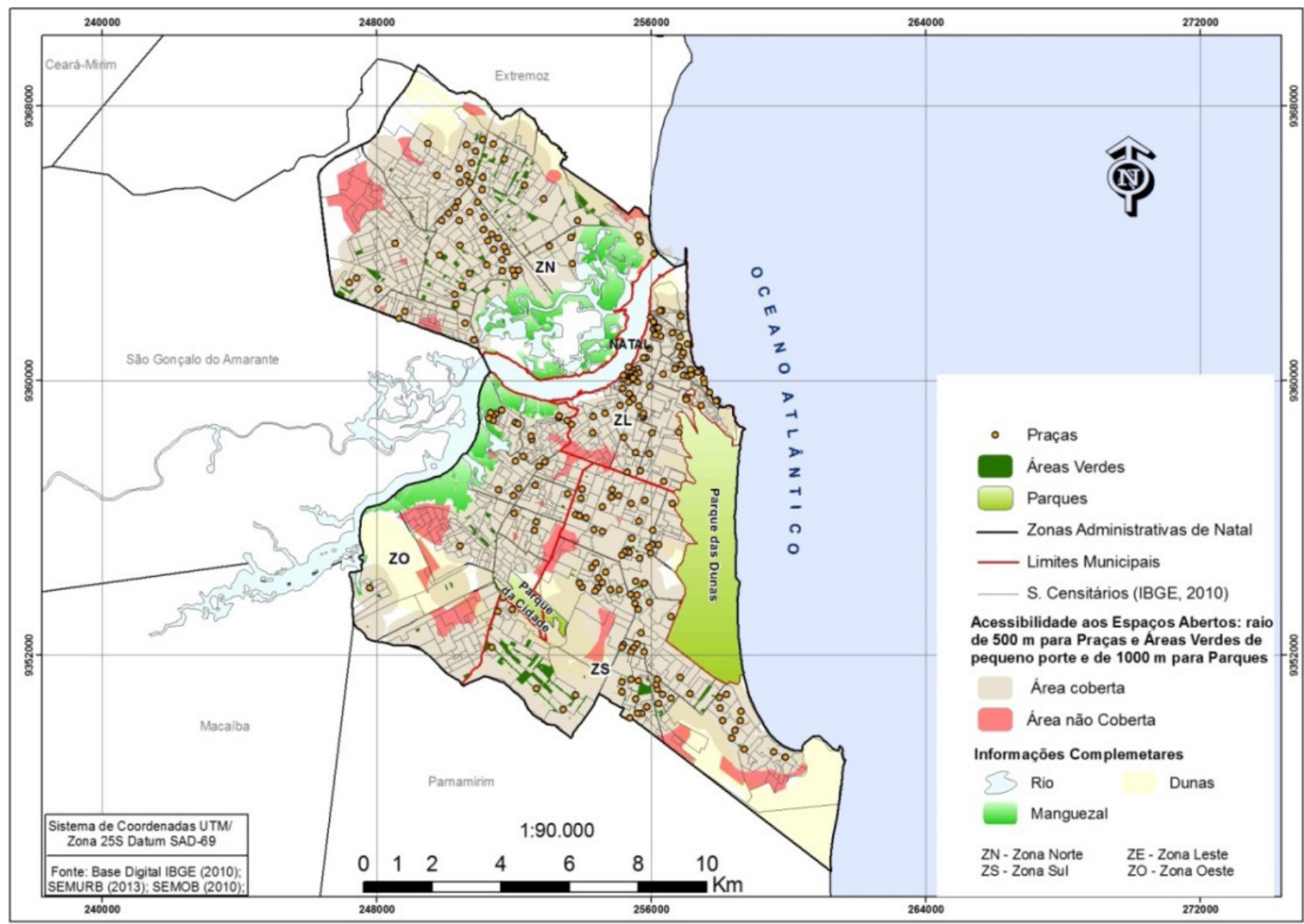

Org. das autoras.

Conforme os resultados da avaliação acerca da Acessibilidade aos espaços abertos, Natal apresenta aproximadamente $93 \%$ dos domicílios inseridos na área de cobertura proposta para esse indicador, o que equivale a um valor normalizado de 0,93 , representando um excelente resultado para a cidade. Dentre os 7\% de domicílios localizados fora da área de cobertura (17.093), a maioria situa-se nos bairros periféricos das zonas Sul, Norte e Oeste da cidade (Figura 4).

O Bairro Nossa Senhora da Apresentação, com
4.105 domicílios, é o que tem a maior incidência de residências fora da área de cobertura determinada para esse indicador, o que corresponde a um valor maior que a soma dos domicílios dos bairros de Ponta Negra (1.797) e Igapó (1.598), que detém a segunda e terceira maior quantidade domicílios inseridos fora da área de cobertura, respectivamente. O Bairro do Alecrim, localizado na zona leste, também se destaca com 1.580; embora algumas áreas sejam residenciais, predomina o comércio e a prestação de serviços, existindo poucas áreas abertas destinadas ao lazer (Figura 5). 
É importante ressaltar que, apesar da quantidade de praças e áreas verdes em Natal ser bem expressiva, o acesso com qualidade não é garantido, visto que uma grande parte desses equipamentos de lazer e recreação, principalmente aqueles localizados na periferia, encontram-se em péssimas condições de uso. Essa situação é reforçada por Amaral (2013), ao afirmar que mais de 80\% das praças e canteiros da cidade precisam de manutenção.

Figura 5. Domicílios externos ao raio de cobertura de espaços aberto por bairro em Natal/RN

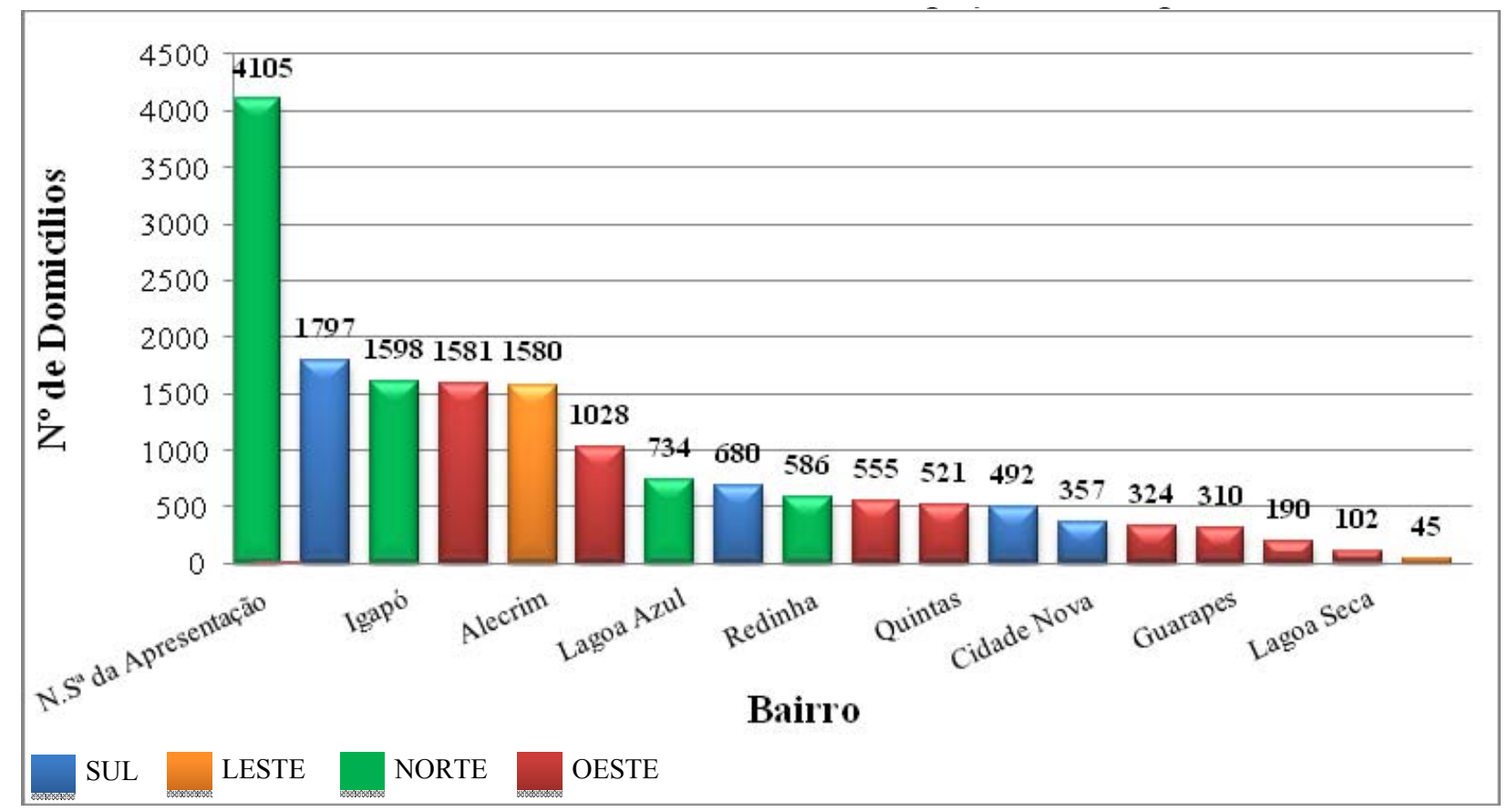

Org. das autoras.

Quanto aos parques urbanos, apenas o Parque Estadual das Dunas está aberto ao público. O Parque da Cidade Dom Nivaldo Monte encontra-se interditado por diversos motivos, entre eles, financeiro e de gestão.

\section{Acessibilidade ao transporte público em Natal/RN}

$\mathrm{Na}$ análise para o Indicador de Acessibilidade ao Transporte Público é considerada a porcentagem dos domicílios situados na área de cobertura de um raio de 300 metros de um ponto de acesso aos serviços de transporte público, considerando todos os modos disponíveis.

A Agência Nacional de Transporte Público (ANTP, 1995) define ponto de acesso aos serviços de transporte público, ou simplesmente ponto de parada, como o local estabelecido na via pública onde se realiza a parada do veículo de transporte coletivo para o embarque e/ou desembarque de passageiros.
Em Natal, as definições do local e do tipo dos pontos de parada de transporte público são atribuições da Secretaria Municipal de Mobilidade Urbana (SEMOB). O sistema de transporte público por ônibus está estruturado em 22 terminais, sendo 2 localizados na Zona Sul; 3, na Zona Leste; 7, na Zona Oeste; e 10, na Zona Norte da cidade. A frota operacional do sistema é constituída de 714 ônibus dos quais 630 compõem a frota efetiva, que operam 91 linhas, sendo que 13 possuem operação compartilhada entre duas ou mais empresas. O transporte opcional, também denominado de alternativo, é composto por 177 veículos do tipo Van, que operam 27 linhas, as quais, em alguns trechos, se sobrepõem as linhas de ônibus. Ao longo dessas linhas, encontram-se 1.693 pontos de paradas de transporte coletivo (SEMOB, 2010), conforme pode ser visualizado na Figura 6.

A análise para o Indicador de Acessibilidade ao Transporte Público mostrou que $92,83 \%$ das residências situam-se a uma distância de até 300 metros 
Espaço, iniquidade e transporte público: avaliação da acessibilidade urbana na cidade de Natal/RN por meio de indicadores de sustentabilidade Luzimar Pereira da Costa, Ione Rodrigues Diniz Morais

dos pontos de paradas de ônibus e/ou opcionais. A avaliação para esse indicador ficou em torno de 0,9 , o que representa um resultado aceitável.

No que tange ao cálculo dos domicílios fora do raio de cobertura determinado para esse indicador, os dados mostram que 16.877 domicílios de Natal localizam-se a uma distância superior a 300 metros da parada de transporte público. Esse valor representa $7,17 \%$ do total de domicílios registrados pelo IBGE no município (2010).

Figura 6. Acessibilidade ao transporte público em Natal/RN

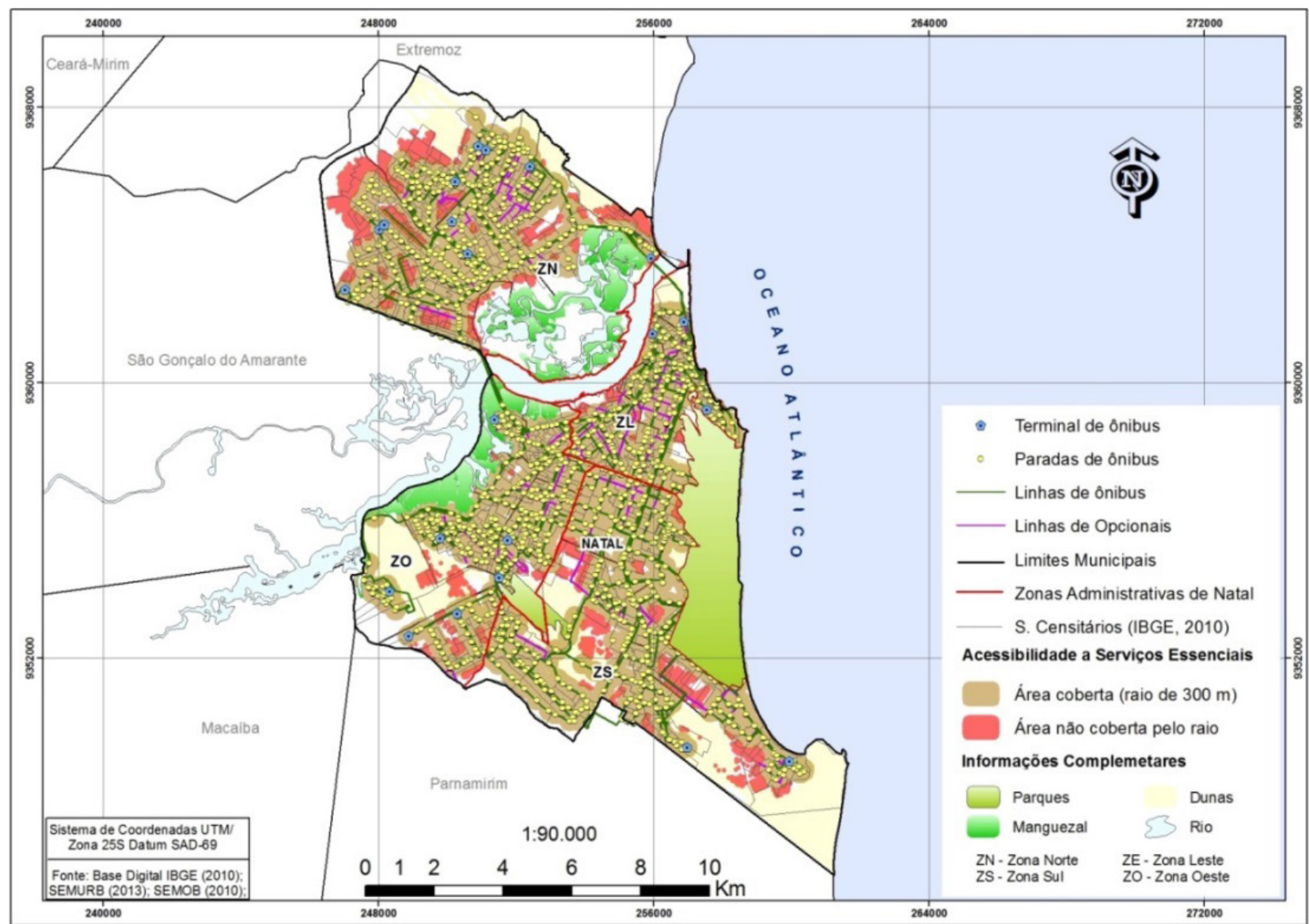

Org. das autoras.

Os dados também permitem aferir que, apesar da Zona Norte ter a maior quantidade de terminais de ônibus, os bairros que a compõem são os que apresentam o maior número de domicílios distantes dos pontos de parada. Nessa zona destacam-se os bairros Nossa Senhora da Apresentação, Lagoa Azul, Redinha, Igapó e Pajuçara (Figura 7). 
Figura 7. Domicílios externos a área de cobertura de 300 metros de distância das paradas de transporte público por bairro em Natal/RN

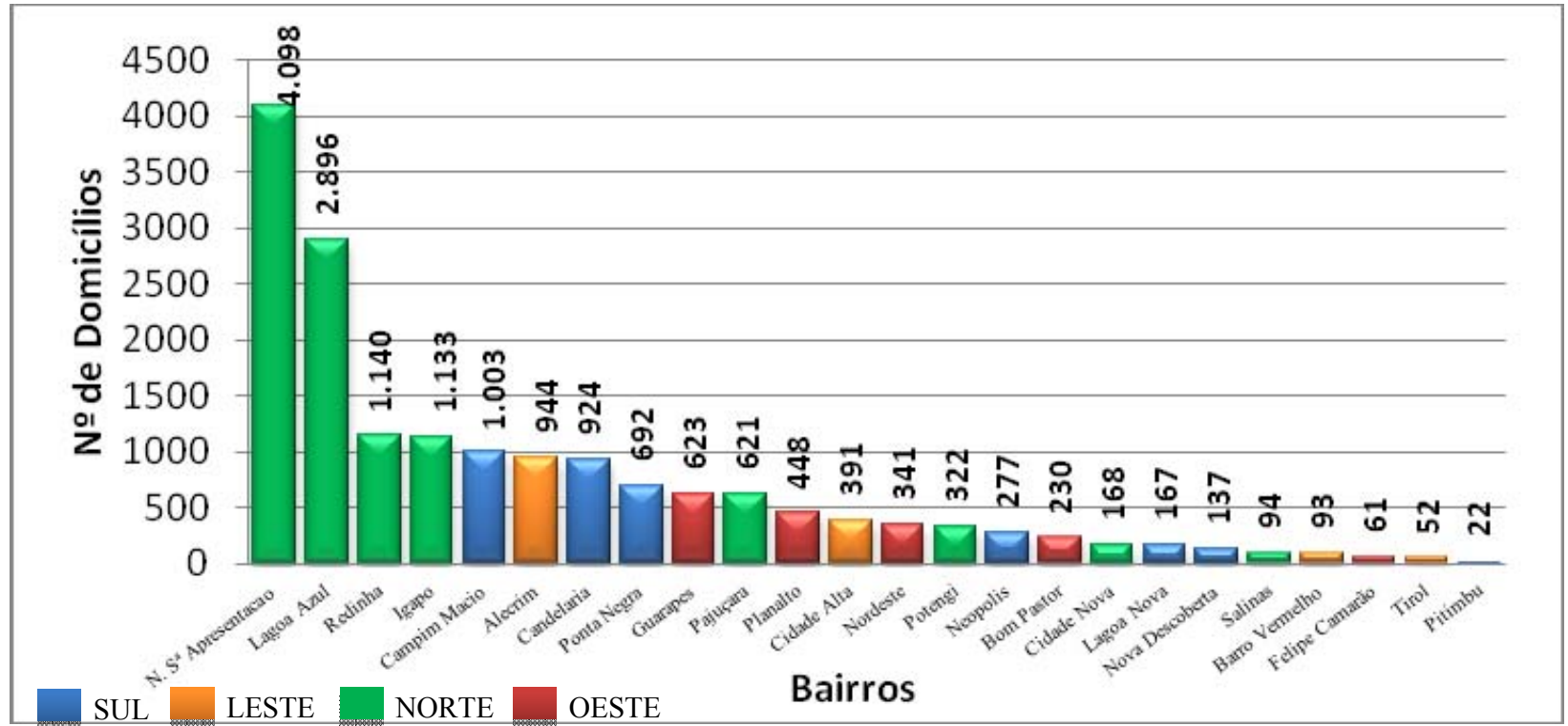

Org. das autoras.

No que se refere à acessibilidade a destinos, além de maiores distâncias a percorrer e dos serviços precários de transporte, a população da Zona Norte da cidade vivencia, ainda, longos congestionamentos nos horários de maior fluxo no trânsito, ocorrendo, principalmente, nas cabeceiras da Ponte de Igapó. Esse fato se reflete no tempo de espera do transporte público que, muitas vezes, chega ao ponto de parada já lotado, ocasionando desconforto ao usuário durante a viagem. Evidentemente que, por se localizar mais distante das áreas centrais de Natal, os moradores dos bairros da Zona Norte gastam mais tempo no trânsito.

Todavia, salienta-se que o tempo gasto para deslocamento na cidade como um todo tem aumentado no decorrer dos últimos anos, devido ao crescimento do fluxo de veículos, o que se reflete em congestionamentos nas principais vias expressas, cujos destinos são os locais onde se encontram os Polos Geradores de Viagem, ou seja, empreendimentos de grande porte que atraem ou produzem grande número de viagens, tais como: shoppings, hipermercados, bares e restaurantes, lojas, escritórios, hotéis, universidades, entre outros. Para efeito comparativo, ressalta-se que, segundo dados do Sindicato de Transporte Urbano do Rio Grande do Norte (SETURN), em 2007, o percurso da linha de ônibus 33, cujo itinerário é realizado entre os bairros Planalto e Mãe Luiza, localizados nas zonas Oeste e Leste, respectivamente, era feito em 75 minutos. Hoje, o tempo oficial é de 110 minutos, 46\% maior que o registrado há seis anos, podendo ser ainda mais demorado em horários de grande fluxo.

\section{CONSIDERAÇÕES}

De acordo com o exposto, verifica-se que os indicadores referentes à acessibilidade urbana, analisados para a cidade do Natal, incidiram em bons resultados. No entanto, quando esses indicadores foram analisados separadamente, respeitando os limites de bairros e Regiões Administrativas de Natal, verificou-se que existem iniquidades inerentes a esses espaços.

A camada da população que reside na periferia de Natal, principalmente nos bairros das zonas Norte e Oeste da cidade vivenciam problemas decorrentes da ausência ou precariedade na infraestrutura urbana tendo em vista que as necessidades de equipamentos públicos considerados fundamentais, como escolas, unidades básicas de saúde, áreas de lazer, entre outros, não são supridas de forma adequada. Isso faz com que a população, diante da impossibilidade de atendimento das necessidades básicas no próprio bairro onde mora, se desloque, diariamente, para outras áreas da cidade a 
fim de supri-las. No entanto, a parcela que depende do transporte público, continua tendo suas oportunidades reduzidas por não dispor desse serviço com qualidade.

Sendo assim, percebe-se que o tratamento dado ao problema de acessibilidade urbana em Natal não tem se mostrado adequado às distintas realidades locais. A cidade, atualmente, atinge mais de trezentos mil veículos, sem possuir uma estrutura compatível para atender a essa frota. Ademais, verifica-se a ausência de infraestrutura adequada para os segmentos mais carentes da população, além da má qualidade e do preço oneroso do serviço de transporte público. Nesse contexto, há uma percepção geral de que o tratamento dado à questão de mobilidade e acessibilidade urbanas, até o momento, não tem se refletido em resultados condizentes com a realidade da cidade, gerando insatisfação da população em decorrência das condições que envolvem o deslocamento pelo espaço urbano.

Recentemente, o reajuste da tarifa do transporte público em diversas cidades brasileiras, incluindo Natal, estimulou a população a demonstrar insatisfação, culminando, assim, em grandes manifestações que surgiram, inicialmente, com o movimento de estudantes para contestar o aumento da tarifa do transporte público. Contudo, no decorrer dos eventos, outros segmentos da população passaram a apoiar as mobilizações e promover reivindicações, acrescentando temas de interesse coletivo, como os gastos públicos com eventos esportivos, envolvendo, principalmente, a Copa das Confederações e a Copa do Mundo de 2014; corrupção na política; melhores investimentos no setor de saúde e de educação, entre outras reivindicações.

Diante do exposto, torna-se evidente que os serviços e equipamentos urbanos em Natal precisam ser urgentemente melhorados por meio da efetivação de políticas públicas em diversas áreas. No que tange, especificamente, à mobilidade urbana, melhorar as condições de acessibilidade é um grande desafio e o IMUS, por ser uma ferramenta capaz de avaliar muitos aspectos relacionados à mobilidade urbana, entre eles, a acessibilidade, pode ser um importante instrumento para o setor de planejamento. Conforme Rodrigues da Silva et al. (2008), o IMUS pode ser aplicado ao contexto de qualquer cidade.

A análise de indicadores, conforme previsto, reduziu uma grande quantidade de informações a um número que pode ser facilmente analisado, possibilitando a interpretação de informações relevantes para a cidade do Natal. Além disso, o uso de softwares do SIG facilitou as análises, o que confirma os argumentos de Calijuri e Röhm (1994) de que, por meio dos SIGs, é possível realizar uma série de análises no espaço urbano, tais como: otimizar o sistema de transporte público; planejar formas de avanço das redes de infraestrutura; definir locais estratégicos para instalação de escolas, creches, postos de saúde, áreas de lazer, etc.

Portanto, o estudo baseado na aplicabilidade do IMUS na cidade do Natal possibilitou identificar as áreas com maiores desigualdades na oferta de serviços e de infraestrutura que interferem no deslocamento da população, limitando suas oportunidades. Logo, os indicadores que contemplam a distância entre a casa, o trabalho e outros espaços e o tempo necessário para cumprir esses percursos são de suma importância para a análise da acessibilidade, já que evidenciam os espaços onde ocorrem as maiores iniquidades.

\section{REFERÊNCIAS}

ANTP. Pontos de parada de ônibus urbano: Caderno técnico n. 2. São Paulo: Associação Nacional de Transportes Públicos, 2005.

AMARAL, E. Mais de $80 \%$ das praças de Natal estão sem manutenção. Tribuna do Norte, Natal, 19 maio 2013.

CALIJURI, M. L; RÖHM, S. A. Sistema de informações geográficas. Viçosa: CCET/DEC. Imprensa da Universidade Federal de Viçosa: Viçosa, 1994. 34 p.

CARDOSO, C. E. P. Análise do transporte coletivo urbano sob a ótica dos riscos e carências sociais. 2008. 139 f. Tese (Doutorado em Serviço Social) - Pontifícia Universidade Católica de São Paulo, São Paulo, 2008.

COSTA, A.A. A verticalização e as transformações do espaço urbano de Natal - RN. 2000. 207f. Tese (Doutorado em Geografia) - Universidade Federal do Rio de Janeiro, Rio de Janeiro, 2000. 
COSTA, M. S. Um índice de mobilidade urbana sustentável.2008. 274 f.Tese (doutorado em Planejamento e Operação de Sistema de Transporte) - Escola de Engenharia de São Carlos. Universidade de São Paulo, São Carlos, 2008.

FLICK, U. Introdução à pesquisa qualitativa. 3. ed. Porto Alegre: Artmed, 2009.

GIL, A. C. Como elaborar projetos de pesquisa. 4. ed. São Paulo: Atlas, 2007.

GOMIDE, A. A. Mobilidade urbana, iniquidade e políticas sociais. Políticas Sociais: acompanhamento e análise, Brasília, n.12, p. 242-250, fev. 2006.

IBGE. Censos demográficos de 2000 e 2010. Disponível em: $<$ http://www.ibge.gov.br/ho me/>. Acesso em: 13 mar. 2013

IDEMA. Perfil do seu municipio - Natal. Natal, Governo do Estado do Rio Grande do Norte, 2008. 1 CD-ROM.

LEFEBVRE, H. La production de l'espace. 4. ed. Paris: Éditions Anthropos, 2000.

LITMAN. T. Evaluating accessibility for transportation planning: measuring people's Ability to reach desired goods and activities. Victoria Transport Policy Institute, Canadá, 2012.

LITMAN. T. Reinventing transportation: exploring the paradigm shift needed to reconcile transporttation and sustainability objectives. Victoria Transport Policy Institute, Canadá, n.12, p.01-12, 2003.

LOBODA, C.R; DE ANGELIS, B. L. D. Áreas verdes públicas urbanas: conceitos, usos e funções. Ambiência. Guarapuava, v.1 n. 1, p. 125-139, jan./jun. 2005.

MIRANDA, H. F.; SILVA, A. N. R. Benchmarking sustainable urban mobility: The case of Curitiba, Brazil. Transport Policy, v. 21, p. 141-151, 2012.
MONDARDO, M. L. Meandros na produção do espaço urbano: mobilidade, acessibilidade e exclusão social. Boletim Goiano de Geografia, Goiânia, v. 29. N. 1, p. 57-71, 2009.

MOURELO, A.C. A. Un Sistema de Indicadores para Avanzarenla Movilidad Sostenible. In: $5^{\circ}$ CONGRESO DE INGENIERÍA DEL TRANSPORTE, 2002. Actas... Santander, 2002.

PEREIRA, S. R. Percursos urbanos: mobilidade espacial, acessibilidade e o direito à cidade. In: $10^{\circ} \mathrm{COLOQUIO}$ INTERNACIONAL DE GEOCRÍTICA, 2008, Barcelona. Barcelona. Actas..., Barcelona, 2008. p. 26-30.

RODRIGUES DA SILVA, A. N. Development and Application of I_SUM - An Index of Sustainable Urban Mobility. In: ANNUAL MEETING OF THE TRANSPORTATION RESEARCH BOARD WASHINGTON, 89, 2010, Repositórium Universidade do Minho, Braga, 2010.

SANTOS, M. A natureza do espaço. 4. ed. São Paulo: Edusp, 2004.

SANTOS, M. et al. Território: globalização e fragmentação. São Paulo: Hucitec, 1996.

SILVA JÚNIOR, R. F.; RUTKOVSKI, G. J. Fragmentação urbana, (re)produção da cidade e evolução da mobilidade em Irati/PR: uma análise pelo transporte público. Entre-Lugar, Dourados, ano 2, n. 4, p. 17-38, $2^{\circ}$ semestre de 2011.

TORQUATO, A. M. S. C.; SANTOS, E. Políticas de Transporte e Pobreza Urbana: Reflexões e evidências em um Bairro Periférico de Natal. In: CONGRESSO DE PESQUISA E ENSINO EM TRANSPORTES ANPET, 2004, Florianópolis. Anais... Florianópolis: UFSC, v.2, 2004.

VASCONCELLOS, E. A. Transporte urbano, espaço e equidade: análise das políticas públicas. São Paulo: Annablume, 2001.

VILLAÇA, F. Espaço intra-urbano no Brasil. São Paulo: Studio Nobel: FAPESP: Lincoln Institute, 2001. 